\title{
Overview paper on: low voltage direct current (LVDC) distribution system standards
}

\section{Kyle Smith*, Dong Wang, Abdullah Emhemed, Stuart Galloway and Graeme Burt}

Department of Electronics and Electrical Engineering,

University of Strathclyde,

Glasgow, UK

Email: kyle.smith@strath.ac.uk

Email: d.wang@strath.ac.uk

Email: abdullah.emhemed@strath.ac.uk

Email: stuart.galloway@strath.ac.uk

Email: graeme.burt@strath.ac.uk

*Corresponding author

\begin{abstract}
Low-voltage direct current (LVDC) systems have recently been recognised as one of the key enabling technologies that can facilitate the connection of more distributed renewables with improved efficiency and enhanced controllability. However, there is still a shortage of mature experience and practical technical solutions that can support the uptake of such systems and increase commercial interest. One of the barriers is the lack of standards necessary to increase industry confidence. Recently, new standard activities at national and international levels have begun to cover specific LVDC applications. However, it is still not clear whether these activities, in addition to existing standards, are sufficient and comprehensive to provide the necessary tools for best practice system design. This paper therefore reviews and evaluates the available LVDC standards within the context of the established $\mathrm{AC}$ distribution system to determine where future work is required.
\end{abstract}

Keywords: distribution systems; low voltage direct current; standards.

Reference to this paper should be made as follows: Smith, K., Wang, D., Emhemed, A., Galloway, S. and Burt, G. (201X) 'Overview paper on: low voltage direct current distribution system standards', Int. J. Power Electronics, Vol. XX, No. YY, pp.XXX-XXX.

Biographical notes: Kyle Smith is a $\mathrm{PhD}$ candidate at the University of Strathclyde with a focus on LVDC distribution networks. He has a ME in Mechanical Engineering from the University of Edinburgh and previously worked in wind energy and community energy development.

Dong Wang received the BE in Electronic \& Electrical Engineering from the University of Strathclyde and his MSc from University of Southampton. He is currently a $\mathrm{PhD}$ candidate at the University of Strathclyde with a focus on LVDC distribution and the integration of protection solutions into power converters.

Abdullah A. S. Emhemed (M07) received the BE in Electrical Power Systems from Nasser University, BaniWaleed, Libya, and PhD from University of Strathclyde, Glasgow, UK in 2010. He is a member of the IET TC2.4 on LVDC, and the IEC SEG4 on LVDC. He is currently a Researcher within the Institute for Energy and Environment at the University of Strathclyde. 
Stuart Galloway is a Reader within the Institute for Energy and Environment. $\mathrm{He}$ obtained his $\mathrm{MSc}$ and $\mathrm{PhD}$ in mathematics from the University of Edinburgh in 1994 and 1998, respectively. His research interests include power system optimisation, numerical methods and simulation of novel electrical architectures.

Graeme M. Burt (M95) received the BE in electrical and electronic engineering from the University of Strathclyde, Glasgow, UK, in 1988 and the PhD in fault diagnostics in power system networks from the University of Strathclyde in 1992. Currently, he is a Professor at the University of Strathclyde, and is Director of the University Technology Centre in Electrical Power Systems, sponsored by Rolls Royce.

\section{Introduction}

The use of direct current (DC) power distribution is not new. In fact, it was the first standard electrical distribution system at the end of the 19th century (Lobenstein and Sulzberger, 2008). However, at the time, the inability to transform DC voltages limited the use of DC to local power stations close to electrical loads. The introduction of alternating current (AC) in 1880s and the invention of transformers facilitated the transmission of power over long distances; $\mathrm{AC}$ systems have since become fundamental to the operation of modern, highly interconnected power systems. The growth of public $\mathrm{AC}$ power networks quickly relegated the use of DC to specific applications such as trams, elevator motors and battery-operated systems. But, as shown in Figure 1, the development of industrial power electronics such as the mercury arc valve in 1902 and the transistor in 1947 has allowed DC systems to evolve over the past century and we now see DC power used in high voltage transmission lines, consumer electronics and industrial variable speed drives (Tiku, 2014). However, these modern applications for DC power distribution remain in isolated systems with limited networking and load heterogeneity.

Figure 1 A brief history of DC power distribution (see online version for colours)

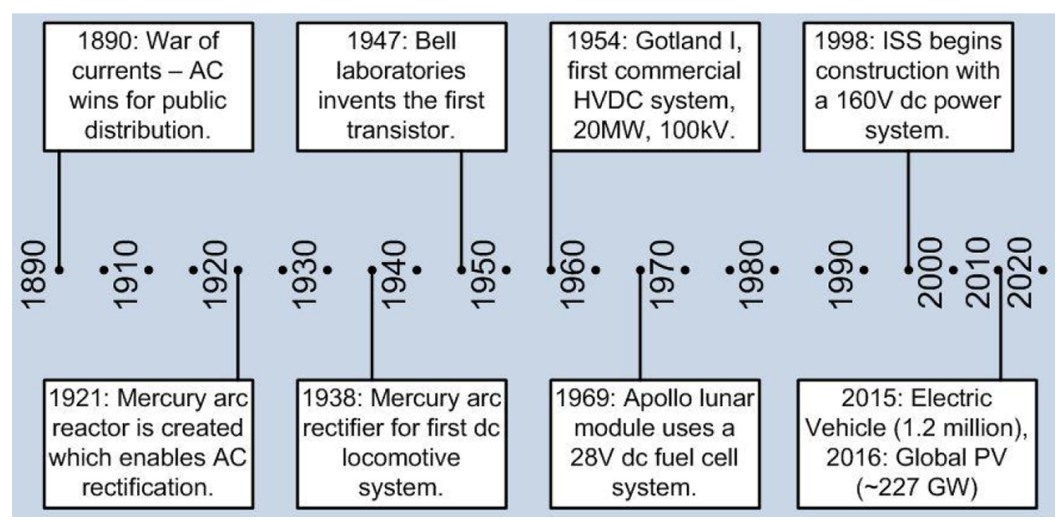


More recently, the increased understanding and concern about the effects of centralised fossil fuelled power stations on the environment has initiated a clean power revolution that is starting to challenge the 100 -year old power system paradigm. Modern, renewable power generators are geographically distributed and either produce DC power natively or utilise DC to regulate the power generation from variable speed generators, such as wind turbines. Furthermore, the technical advancement in lithium ion batteries since the turn of the millennium has seen the cost reduction and energy density reach a level where electric vehicles are becoming a real proposition for mainstream consumers (International Energy Agency, 2016). This increasing volume of DC generators, modern electronic loads and energy storage systems raises the question as to whether DC distribution would be a more efficient and economical public power distribution medium. If DC power is to challenge the predominance of $\mathrm{AC}$ in low voltage public distribution networks, a new set of technical standards are required to facilitate harmonised voltages and power quality, suitable protection solutions and new safety regulations.

This paper seeks to assess the current state of LVDC standards and to highlight the work that is required to reach a similar level of standardisation compared to existing LVAC public distribution systems. Research papers (Elsayed et al., 2015; Monadi et al., 2015; Dragicevic, T. et al., 2015 \& 2016) present excellent overviews of LVDC distribution and protection options. However, this article is the first review that has collated and evaluated the available LVDC system standards to assess the status of LVDC applications and the gaps that may limit the development of LVDC distribution systems. This is presented as an introduction to the active organisations currently developing LVDC standards, followed by a focused review on the power quality, protection and safety requirements for LVDC applications and future public distribution networks.

\section{Applications and standards development}

The LVDC systems under consideration in this paper are depicted in Figure 2 and a growing number of international standards organisations are developing requirements for the design and safe implementation of these LVDC applications. Most of the standards reviewed within this paper are outputs from the following organisations:

Figure 2 Overview of LVDC distribution systems (see online version for colours)

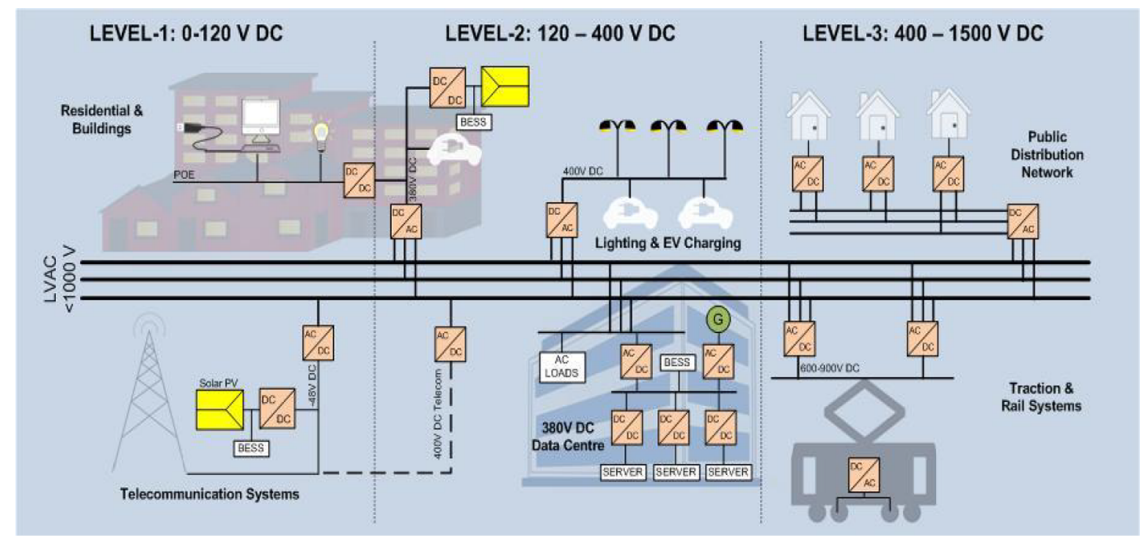




\subsection{International Electrotechnical Commission}

The International Electrotechnical Commission (IEC) has recognised the need for introducing new standards that can enable the integration of LVDC technologies within existing AC systems in a secure and optimised way. In November 2014, the IEC established the Systems Evaluation Group (SEG4) to evaluate LVDC applications, distribution and safety for use in developed and developing economies (Fachot, 2015). The final report from the IEC SEG4 (IEC SEG4, 2016) has stated that "a very large number of publications, issued by over 30 IEC Technical Committees (TCs), are concerned and will need updating" in order to add the standards requirements for DC into existing AC standards. In order to address such requirements, the IEC Standardization Management Board (SMB) approved in February 2017 the establishment of a new Systems Committee on LVDC \& LVDC for Electricity Access (IEC, 2017).

\subsection{IEEE Standards Association}

The IEEE Standards Association has a number of working groups focused on the use of DC distribution for specific applications. The most general working group is WG 946 DC System Design which is in the process of developing P946 - Recommended Practice for the Design of DC Power Systems for Stationary Applications. Further to this, the Distribution Resource Integration working group has developed P2030.10 - Standard for DC Micro-grids for Rural and Remote Electricity Access Applications (IEEE, 2016). Meanwhile, WG 1709 exists for the development of standards for DC power systems on ships and a series of working groups exist focused on the safe design of DC traction systems for transportation which includes protection, insulation and corrosion design standards. Furthermore, in 2013, an IEEE working group was established to investigate the required standards for 'DC in the home', and the research topics included sockets, safety equipment and breakers (Wiebe, 2013).

\subsection{IET standards}

The Institution of Engineering and Technology (IET) has recently published two documents related to LV and Extra LV DC distribution standards. The IET Technical Committee (TC2.4) has developed the "Code of Practice for Low and Extra Low Voltage Direct Current Power Distribution in Buildings" and the accompanying technical briefing "Practical Considerations for DC Installations" (IET, 2015c).

\subsection{EMerge Alliance}

The organisation, EMerge Alliance, exists for the specific purpose of developing crossindustry standards for the adoption of building level and data centre DC distribution systems. The organisation has published two standards: the Occupied Space Standard and Data/Telecom Standard. EMerge Alliance is currently leading the development of DC distribution systems with a broad consortium of industry and academic partners. They maintain a registry of products that conform to the EMerge Alliance standards and have a vision to develop standards for occupied spaces, residential buildings, data centres, outdoor spaces and building services (EMerge Alliance, 2016). 


\subsection{Cigre}

Working group B4 of Cigre focuses on HVDC and Power Electronic research for distribution networks. Working group C6.31 Medium Voltage Direct Current (MVDC) Grid Feasibility Study is a new group that is considering the prospect of future MVDC distribution systems. As yet, there does not appear to be a working group for LVDC within Cigre.

\subsection{National standards}

The design of residential and building level DC distribution systems is governed by BS7671 in the UK and the National Electric Code (NEC) regulations in the US. To date, BS7671 contains guidance for the DC connections and cabling requirements with respect to solar PV installations as well as requirements on RCD clearance times according to earthing arrangements but does not make specific recommendations on DC distribution voltage levels or the protection requirements for more complex DC systems (IET, 2015a). In the $2017 \mathrm{NEC}$ edition, there are sections dedicated to the implementation of DC micro-grids (712), solar PV (690), energy storage (706) and direct current bonding (250). Other national standards such as the Indian National Electric Code define a DC distribution voltage level as $220 / 440 V_{D C}$ and provide guidelines on cable colours, fault current calculations and solar PV recommendations (Bureau of Indian Standards, 2011). Japan specifies the upper limit of low voltage DC at $750 V_{D C}$ and China currently has national standards in the area of DC-powered telecom installations (IEC SEG4, 2016).

\subsection{Bespoke installations and research projects}

International research and commercial pilot projects are advancing the understanding and capabilities of public DC distribution systems that will ultimately inform future national and international standards. A summary of recent LVDC projects are presented in Table 1, collectively, these research themes are advancing the development of technically and economically viable DC distribution networks.

Table 1 Selected existing LVDC pilot projects and research themes

\begin{tabular}{lll}
\hline Project & Application & Reference \\
\hline DC Smart & DC distribution smart grids & TU Delft (2016) \\
dcProject & Building level LVDC & $\begin{array}{l}\text { Alliance for Sustainable Colorado } \\
(2016)\end{array}$ \\
& Building level LVDC & Wunder et al. (2014) \\
DCC+G & Industrial/Factory LVDC & Ravula (2015) \\
Bosch-Honda Micro-grid & LVDC for MVAC networks & Nuutinen (2015) \\
LUT, Elenia, ABB & Protection of DC systems & Emhemed and Burt (2014) \\
University of Strathclyde & Control strategies for DC & Dragicevic et al. (2015) \\
University of Aalborg & micro-grids & \\
& Stability of DC systems & Purdue University (n.d.) \\
Purdue University & & \\
\hline
\end{tabular}




\section{DC voltage level and power quality requirements}

The following section introduces the existing and emerging LVDC applications according to their operating voltage ranges. The most appropriate standards that relate to these applications were reviewed to determine the adequacy of existing guidelines and to identify any gaps that might limit the safe and cost-effective development of these applications and future public DC distribution systems.

\subsection{Operating voltage levels}

The European Union Low Voltage directive (LVD 72/23/EEC) states that low voltage equipment can possess voltage ranges of 40-1000 $V_{A C}$ and between 75 and $1500 V_{D C}$ (The European Parliament and the Council of the European Union, 2006). This range sets the boundaries for LVDC; however, further voltage classification can occur within this range. This paper defines three voltage levels, which are depicted in Figure 2 in order to examine the protection and safety standards for applications with similar operating characteristics.

\subsubsection{Level-1 applications $\left(<120 V_{D C}\right)$}

In this paper, Level 1 is considered to be $<120 \mathrm{~V}$, which represents the extra-low voltage range of LVDC according to IET (2015b). At this voltage level, the primary design concern is cable insulation thermal degradation caused by excessive currents, which can lead to insulation faults and electric shock. In addition, voltage drops are a significant design consideration and therefore cable lengths are limited at these voltage levels.

The Universal Serial Bus (USB) is the lowest voltage level considered in this review and is a widely used DC system, which has a safe operating voltage of $5 \mathrm{~V}$ that is common throughout the USB standard; this includes USB 2.0, USB 3.0 and USB type C as depicted in Figure 3. Both USB-IF and IEC have standardised the recommendations for USB (Hewlett-Packard et al., 2013; USB 3.0 Promoter Group, 2014). USB cables often interface with personal computers whose power supply requires a rectifier to transform the AC power to DC. The standard DC output voltage for a desktop computer is $12 \mathrm{~V}$ as specified by ATX12V 2.01 (Intel, 2004). Furthermore, with the introduction of $100 \mathrm{~W}$ USB power transfer capabilities, the opportunity for bi-directional power flow through the USB port becomes a real possibility (Intel \& DisplayLink, 2016).

Figure 3 USB 3.0 port and connector (left) has the same structure as USB 2.0 but possess 9 pins rather than 4 pins. USB Type $\mathrm{C}$ (right) (see online version for colours)
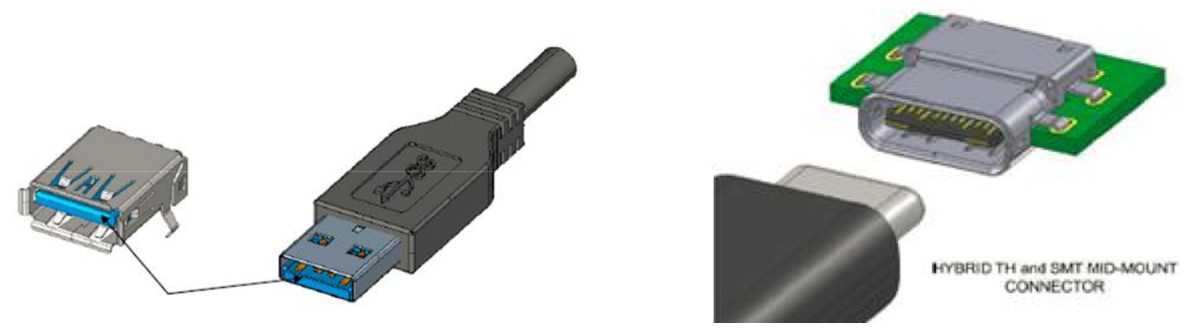

Source: Hewlett-Packard et al., 2016 
Within occupied spaces, there has been a rapid adoption of LED lights due to their higher energy efficiency and quick payback period (Yamada and Stober, 2015). To date, most LED bulbs are operated from the AC power network, with their own internal converter. However, DC LEDs can operate on a dedicated DC network and are proven to be more efficient and can provide higher lighting quality with greater resilience to voltage fluctuations (IET, 2013). BS EN 62560 and BS EN 62384 state that the maximum voltage for lamp controlgear should be within $250 V_{D C}$, and the typical output voltage is $12 / 24 \mathrm{~V}$ for feeding the DC LED lights (IET, 2013). EMerge Alliance has standardised occupied space lighting systems at $24 V_{D C}$ and this requires a room-level converter to step-down the voltage to a safe distribution level (EMerge Alliance, 2016).

The emergence of Power over Ethernet $(\mathrm{PoE})$ has occurred concurrently with the development of LED lighting systems and there appears to be a convergence between LVDC lighting systems and PoE to create intelligent, controllable and efficient buildinglevel lighting systems. In 2003, the IEEE 802.3af standard was published which outlined a transmission power of $15.4 \mathrm{~W}$ at $44 \mathrm{~V}$ over conventional ethernet cables, and this represented the beginning of PoE. In 2009, the standard was upgraded to IEEE 802.3at to meet the demand of higher power applications such as combined power and data cameras, this standard enabled up to $30 \mathrm{~W}$ of transferable power at $44-57 \mathrm{~V}$. The newest standard is currently under development and is scheduled for release in 2016 with a power transfer capability of $95 \mathrm{~W}$ which utilises four paired conductors within the CAT-5 cable (UL, 2015).

The $-48 V_{D C}$ telecom standard utilises an earthed positive pole to create a negative voltage distribution system that offers cathodic protection to surrounding metal work. The voltage level is sufficient for low power telecom systems; however, ETSI (European Telecom Standards Institute) has since introduced a $400 V_{D C}$ standard for higher power and more efficient systems. The ETSI 300 132-2 standard for $-48 V_{D C}$ systems offers detailed specifications for product suppliers and system designers. It states the voltage ranges for normal operations to be -40.5 to $-57 V_{D C}$ and an expectation that there should be no degradation in system performance within this voltage range.

\subsubsection{Level-2 Applications (120-400 $\left.V_{D C}\right)$}

The applications presented in this section have been grouped in the voltage range of 120-400 $V_{D C}$, which represents the upper-end of extra-low voltage DC and the emerging voltage standard for occupied space, data centres and electric vehicle charging (BSI, 2014). In some situations, the applications presented here may also utilise Level-1 or Level-3 voltages which reflects the on-going challenge that standards organisations have in classifying and harmonising DC voltage levels.

The need for higher power services and the growing use of renewable generators has led ETSI to increase the operating voltage of telecom systems from $-48 V_{D C}$ to $400 V_{D C}$ (European Telecommunications Standards Institute, 2011). Furthermore, the rapid increase in data consumption has seen steady growth in the construction of data centres, where the energy demand from these facilities currently amounts to $1.8 \%$ (Shehabi et al., 2016) of national electricity demand in the US. A number of LVDC data centre projects have highlighted significant capital and energy efficiency cost improvements that can be realised using a $380 V_{D C}$ distribution system compared to a traditional $208 V_{A C}$ and even $400 V_{A C}$ (Ailee and Tschudi, 2012). 
With respect to EV charging, 'fast' off-board DC chargers are believed to offer the most practical public charging system based on time to charge and the potential to offer higher efficiencies compared to an on-board charger (Genovese et al., 2015). LVDC distribution can be applied in the form of dedicated EV charging networks where cable costs can be reduced, utilisation rates of a centralised DC charger increased and the integration of DERs can be easily accommodated (Tabari and Yazdani, 2013; Smith K.A. et al., 2016). The performances of these DC charging systems are standardised in BS EN 61851-23:2014 (BSI, 2014) which outlines the protection, power quality and safety requirements.

\subsubsection{Level $3\left(400-1500 V_{D C}\right)$}

The final voltage classification has the largest voltage range which includes traction systems, solar PV, higher power micro-grids and public distribution systems. Traction systems for public transportation are well developed, and there are many examples of DC railway applications such as commuter trains and inner-city trams (TOSHIBA, 2014). Using DC infrastructure takes advantage of lower voltage losses compared to AC systems (Pires et al., 2009). BS EN 50163-1 specifies the recommended voltage levels for traction systems $\left(600 V_{D C}, 750 V_{D C}\right.$ and $\left.1500 V_{D C}\right)$. Most commonly, 600-1000 $V_{D C}$ is used for metros, light rail transit, suburban railways, and $1500 V_{D C}$ is used for overhead lines, which is the most economical solution for heavy metros (Goodman, 2006).

Solar PV has been widely implemented as a competitive and ubiquitous renewable energy source. The generated DC power from these systems can be stored in a complementary Battery Energy Storage System (BESS) or exported to the AC feeder by a DC/AC inverter as shown in Figure 2 (Mahela and Shaik, 2016; Adefarati and Bansal, 2016). BS EN 62548 recommends the voltage for PV systems to be within $1000 V_{D C}$ for buildings without restricted access; however, voltages over $1000 V_{D C}$ are permitted if the entire solar array and associated electrical equipment are restricted to the public.

Utility-level LVDC distribution networks are arguably the least developed concept compared to the other DC applications discussed in this paper. These DC networks are capable of interconnecting renewables and advanced electronic applications with reduced conversion and distribution losses (Elsayed et al., 2015) while potentially enhancing the power carrying capabilities of existing cable assets (Antoniou et al., 2013). Figure 2 of Section 2 highlights a trial public LVDC network deployed in Finland with a bi-polar voltage of $\pm 750 V_{D C}$ (Nuutinen et al., 2014).

Figure 4 depicts an islanded DC micro-grid with multiple generating sources connected to a common DC bus and DC/AC inverters to power variable speed drives at optimum efficiency. This topology can be applied to a ship-based power system as demonstrated in ABB's DC on-board project, but it could equally be applied to industrial applications such as mining sites, waste water treatment and manufacturing factories (Hebner et al., 2015). In Germanischer Lloyd SE (2016), it states that the marine power system DC voltage should be within $1500 V_{D C}$ and as such the ABB DC ship on-board system uses a $1000 V_{D C}$ distribution voltage. This marine DC micro-grid has demonstrated a reduction in the electrical equipment footprint and weight reductions of up to $30 \%$, which yields fuel and emission savings of up to $20 \%$ (ABB, 2014). 
Figure 4 Islanded DC micro-grids for ships and industrial power systems, (see online version for colours)

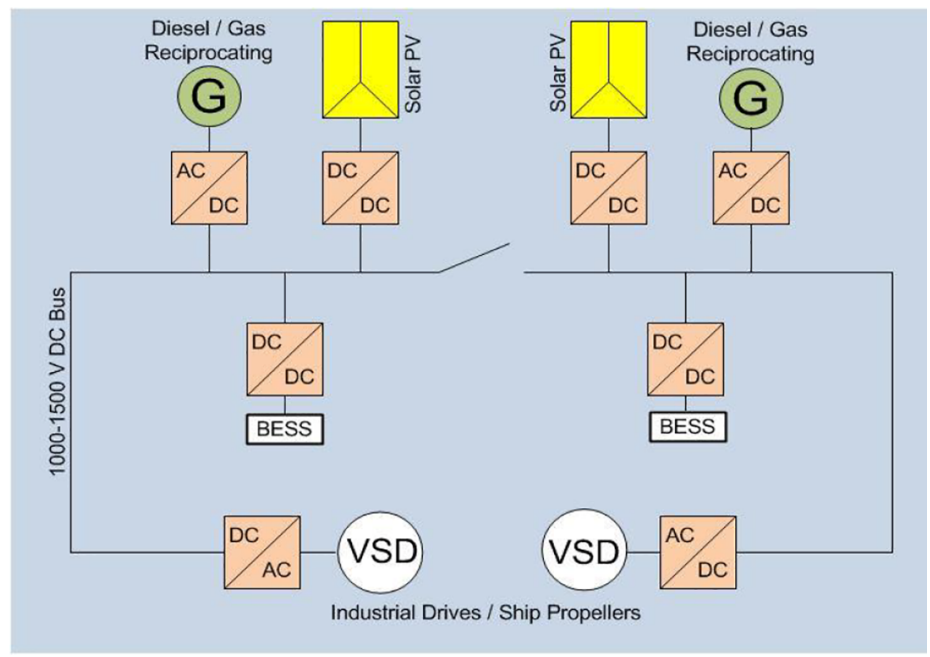

Source: adapted from ABB (2014)

\subsection{Voltage tolerances}

For LVAC public distribution systems, IEC 60038 specifies the expected voltage and tolerances for standard appliance sockets as $230 V_{A C}+10$ and $-6 \%$ (IEC, 2009). This level of harmonisation does not yet exist for public LVDC distribution systems except for specific applications.

The available power quality standards relating to USB systems contain normal operating voltage ranges and acceptable voltage drops that are summarised in Table 2. With respect to voltage drops, the standards specify the following voltage drop limitations on the ground line to be: USB $2.0(125 \mathrm{mV})$, USB $3.0(171 \mathrm{mV})$ and USB type-C $(250 \mathrm{mV})$.

The tolerances for electric vehicle charging infrastructure are detailed in BSI (2014), where the DC charging voltage range should be within $\pm 5 \%$ of the required level with a voltage ripple that is no more than $\pm 5 \mathrm{~V}$. It also states that the charging system should reach the required charging voltage with a slew rate of $20 \mathrm{~V} / \mathrm{ms}$ and must be able to reduce the system voltage at a slew rate of at least $250 \mathrm{~V} / \mathrm{ms}$.

In research conducted by Kaipia et al. (2016), it is suggested that consumer end inverters on a public LVDC distribution networks possess the ability to withstand +10 and $-25 \%$ voltage variations. This is similar to the allowable supply voltage variation for railway applications. 
Table 2 DC voltage tolerances

\begin{tabular}{lccccc}
\hline Application & Nominal voltage & $\begin{array}{c}\text { Min } \\
\text { voltage }\end{array}$ & Max voltage & $\begin{array}{c}\text { Voltage } \\
\text { ripple }\end{array}$ & Standard \\
\hline USB 2.0 & $5 \mathrm{~V}$ & 4.4 & 5.25 & - & IEC 62680-2-1 \\
USB 3.0 & $5 \mathrm{~V}$ & 4.45 & 5.25 & - & IEC 62680-2-1 \\
USB Type-C & $5 \mathrm{~V}$ & & 5.5 & - & IEC 62680-2-1 \\
Desk computer & $12 \mathrm{~V}$ & $-5 \%$ & $+5 \%$ & $<120 \mathrm{mV}$ & ATX 2.01 \\
LED lighting & $12-24 \mathrm{~V}$ & $-10 \%$ & $+10 \%$ & - & BS EN 62384 \\
EV charging & $200-500 \mathrm{~V}$ & $-5 \%$ & $+5 \%$ & $\pm 5 \mathrm{~V}$ & BSI 2014 \\
Marine/Ship & $24 \mathrm{~V}+$ & $-25 \%$ & $+30 \%$ & $\pm 10 \%$ & IEC 60092-101 \\
Railway & $400 \mathrm{~V}+$ & $-33 \%$ & $+25 \%$ & - & BS EN 50328 \\
\hline
\end{tabular}

\subsection{Transient disturbances}

Both telecom and traction system standards have well-defined transient disturbance requirements. The ESTI EN 300 132-2 telecom standard makes specific references to low voltage ride-through criteria and normal operating voltage ranges with error margins. Furthermore, EMC requirements for telecom systems are presented in ETSI EN 300386.

Voltage dips on traction system contact lines are permissible up to $50 \%$ of normal voltage and should not last longer than $1 \mathrm{~s}$. The duration of short interruptions caused by circuit breakers and auto reclosing should be less than 10 s. Finally, BS EN 50121 series provides the electromagnetic compatibility standards for railway systems.

It is clear that each LVDC application has its own unique voltage performance characteristics and this is largely possible due to the known nature of the loads and expected performance of each system. However, in more complex public LVDC networks, a more harmonised approach to voltage standards is required to ensure compatibility between a variety of electrical products and energy sources.

\section{Protection requirements}

\subsection{Protection challenges}

The protection of DC systems is a key research theme for the development of safe and economical LVDC distribution. The challenges relate to DC arc dissipation, due to the absence of a zero crossing-point on the current signal, the speed of protection due to aggression of DC arc (which requires longer time to be quenched) and the rapid DC fault propagation which can lead to tripping of converters and substandard selectivity issues. These challenges are summarised in Emhemed et al. (2016) and the authors suggest improvements to IEC61660 (International Electrotechnical Commission (IEC), 2000) to more accurately characterise short circuit current in complex DC distribution systems (Emhemed and Burt, 2013). 
These characteristics are reflected in the existing protection guidelines, but it is arguable that further standardisation is required in the area of 'complex' LVDC distribution networks, where multiple devices, with varying operating characteristics are connected and therefore selectively isolating only faulted sections of the network enhances power system reliability.

\subsection{Performance guidelines}

For the USB, USB-IF (USB power delivery specification 3.0) and BS EN 62680-2-1 have specified that the power source connected to the USB should implement overcurrent protection and over temperature protection to prevent damage from excessive current and thermal effects (BSI, 2015). IEC 62700 recommends that the short circuit current protection for notebooks comply with IEC 60950. Furthermore, ATX12V specifies that short circuit protection and overvoltage protection should be applied to protect the power supply of desktop computers.

The controlgear for LED lighting systems requires short circuit and overload protection according to BS EN 61347-1. Also, BS EN 61347 2-13 standardises the maximum values of temperature rises under short circuit or overload conditions. Moreover, IET (2013) mentions that fuses and miniature circuit breakers can be utilised at the input of the driver to protect the running of the LED system. For power limited circuits such as LED lighting and POE systems, the NEC725 code presents Class 1, 2 and 3 circuits which specifies the power, voltage and protection requirements for these circuits (National Fire Protection Association, 2017).

In more complex DC distribution, systems such as data centres, fuses and circuit breakers are required to isolate the faulted section of the network. Although BICSI 0022014 and TIA-942-A exist to support data centre design, these established standards do not yet incorporate DC electrical specifications. IEC/TC 64 is tasked with evaluating and standardising the DC electrical content for BS EN 50600-2-2:2014 and will be releasing recommendations in due course. However, ETSI EN 300 132-3-1 specifies expected voltage ranges and protection requirements for telecom systems, radio base stations and data communication equipment, which may be extrapolated for data centres with a distribution voltage less than $400 V_{D C}$.

The protection of telecom infrastructure occurs at what is termed the A3 interface, this is where the generators connect to the Information Communication Technology (ICT). The acceptable voltage range at this interface is between 260 and $400 V_{D C}$ which represents the charge/discharge voltage characteristics of a connected Battery Energy Storage System (BESS). The standard states that the circuit should be protected with either fuses or circuit breakers which meet the requirements of IEC/EN 60269-1, IEC/EN 60947-2 and IEC/EN 60898-2. On start-up of the power system, the in-rush current must be minimised to avoid triggering the over current protection. The protection design should take into consideration system's $\mathrm{T}_{50}$ metric; this describes the duration at which the in-rush current is $50 \%$ of the peak in-rush current $\left(\mathrm{I}_{\mathrm{p}}\right)$ and the energy content $(\mathrm{E})$ of the inrush current can be approximated using $\mathrm{E}=\mathrm{I}_{\mathrm{p}}{ }^{2} \times \mathrm{T}_{50}$ (European Telecommunications Standards Institute, 2011).

The DC protection requirements for traction systems are well defined with several protection options described in standards. BS EN 50123-7-1 relates to the DC switchgear for traction systems and establishes the requirements rate of change of current, inverse time overcurrent protection, inverse time overcurrent with thermal imaging as well as 
under voltage protection. Furthermore, BS EN 50123-1 specifies the recommendations for current limiting circuit breakers for the protection of traction systems at the station locations. This includes the high-speed current limiting breaker (with a total breaking time of $<20 \mathrm{~ms}$ ), very high-speed current limiting circuit breaker (total break time $<4 \mathrm{~ms}$ ) and semi-high-speed circuit breaker (total breaker time $<30 \mathrm{~ms}$ ).

There appears to be limited information relating to protection requirements for integrated solar PV DC distribution systems and electrical loads. At present, the majority of standards relate to solar PV systems that connect directly to the AC network. Therefore, the protection solutions presented here relate to the protection of PV pannel strings and arrays. In BS EN 50123-1:2003, the PV fuse link is specified to 1.45 times normal operating current. Also, BS EN 60269 (BSI 2012) and UL 2579 (Lyons, 2011) have stated the fuse link requirements for protecting the PV system. Furthermore, overcurrent protection is recommended in BS EN 62548-1:2015. Finally, IEC 60364 7-712 states the requirements for the overload and earth fault protection.

Overcurrent protection is also capable of protecting marine power systems. The electrical installation standard for small vessels, IEC 60092-507, recommends DC fuses operate with 1.45 times the lowest current carrying capacity of the conductors in the circuit. Also, IEC 60092-202 provides recommendations on the undervoltage protection for DC generators and DC motors. For personal water-craft, the American Boat \& Yacht Council (ABYC) E11 has specified the overcurrent protection and ground fault protection for $<50 \mathrm{~V} \mathrm{DC}$ electrical systems. However, for larger, more powerful DC marine or landbased micro-grids, the circuit protection requirements are not fully covered in the existing standards and still require further development. Both $1000 V_{D C}$ marine power system and a $\pm 750 V_{D C}$ public distribution system have been deployed by $\mathrm{ABB}$ and the Finish Distribution Network Operator Elenia Oy, which suggests practical protection solutions are available for these higher power distribution systems.

With respect to DC moulded case circuit breakers (MCCB), IEC 60947-2 has specified the standards for DC MCCB, where products are available commercially. However, mechanical-based breakers do not offer the required speed to prevent damage to sensitive power electronics, and this requires more expensive, higher-rated, devices to withstand the fault current. Therefore, significantly faster hybrid solid-state circuit breakers (SSCB) offer a promising solution for LVDC networks; however, this technology is still at the research stage without standard guidelines (Meyer and Rufer, 2006; Shen et al., 2015). Table 3 provides an overview of the commercially available DC fault interruption devices. 
Table 3 Examples of standardised LVDC fault interruption devices (see online version for colours)

\begin{tabular}{|c|c|c|}
\hline \multicolumn{3}{|c|}{ Miniature Circuit Breaker } \\
\hline Brand & $\begin{array}{l}\text { Schneider Electric Acti } 9 \\
\text { (Schneider 2017) }\end{array}$ & ABB S280 (ABB 2007) \\
\hline Operational Voltage & $250 \mathrm{~V} \mathrm{DC} \mathrm{(1P)/500} \mathrm{V} \mathrm{DC} \mathrm{(2P)}$ & 220VDC (1P)/440VDC (2P-4P) \\
\hline Trip Units & Thermal-magnetic & Thermal-magnetic \\
\hline Standards & IEC 60947-2; & IEC 60947-2; \\
\hline Breaking Capacity & $6000 \mathrm{~A}$ at $250 \mathrm{~V}$ DC/500 V DC & $6000 \mathrm{~A}$ at $220 \mathrm{~V}$ DC/440 V DC \\
\hline \multicolumn{3}{|c|}{ Moulded-Case Circuit Breaker } \\
\hline Brand & 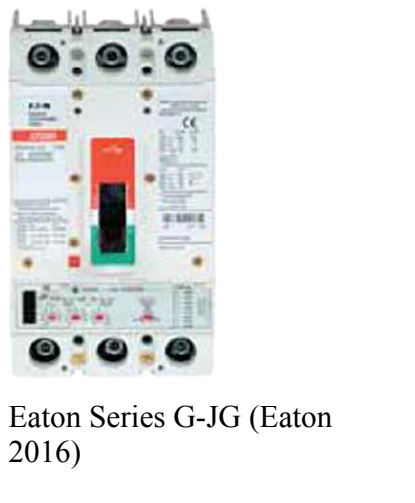 & 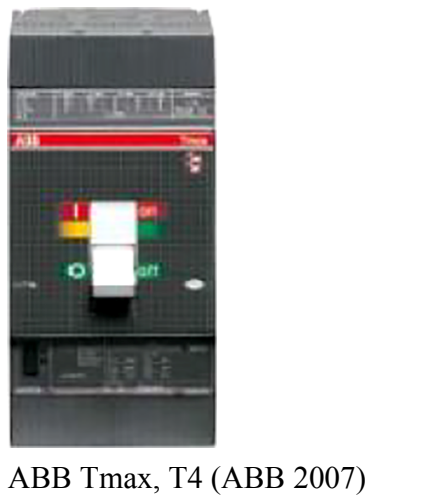 \\
\hline Operational Voltage & $250 \mathrm{~V} \mathrm{DC}$ & $125 \mathrm{~V} \mathrm{DC}, 500 \mathrm{~V} \mathrm{DC}, 750 \mathrm{~V} \mathrm{DC}$ \\
\hline Trip Units & $\begin{array}{l}\text { Fix/Adjustable, } \\
\text { thermal/magnetic }\end{array}$ & Thermal/Magnetic, Electronic \\
\hline Standards & IEC 60947-2 & IEC 60947-2 \\
\hline $\begin{array}{l}\text { Breaking Capacity } \\
\text { Fuse }\end{array}$ & Up to $50 \mathrm{kA}$ at $250 \mathrm{~V} \mathrm{DC}$ & $\mathrm{Up}$ to $150 \mathrm{kA}$ at $250 \mathrm{~V} \mathrm{DC}$ \\
\hline Brand & $\begin{array}{l}\text { Eaton (Bussmann series) } \\
\text { (Eaton 2015) }\end{array}$ & 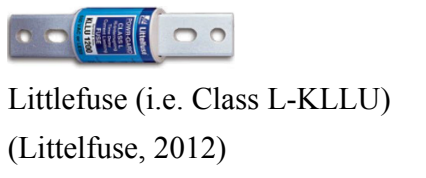 \\
\hline Operational Voltage & $500 \mathrm{~V} \mathrm{DC}$ & $300 \mathrm{~V} \mathrm{DC}$ \\
\hline Trip Units & Thermal & Thermal \\
\hline Standards & IEC/self-certified & Littlefuse self-certified; \\
\hline Breaking Capacity & $50 \mathrm{kA} \mathrm{Max}$ & $20 \mathrm{kA}$ \\
\hline
\end{tabular}




\section{Safety}

With the introduction of LVDC distribution systems into traditional AC networks, a number of additional safety requirements should be considered. These include the impact of running both $\mathrm{AC}$ and $\mathrm{DC}$ cables alongside one another; the effect of corrosion from DC earthing on adjacent metal work; an increased risk of fire due to DC arcing and the risk of stored circuit energy prior to maintenance activities. This section summarises the available safety standards with respect to mitigating the risk of electric shock, corrosion effects and fire safety.

\subsection{Risk of shock}

\subsubsection{Basic protection}

Basic protection refers to the measures that are in place to safeguard the public and livestock from electric shock during normal operating conditions. In the UK, BS7671 and EN BS 61140:2016 present basic protection and standard safety requirements for electrical circuits. The same approach to basic protection can be applied to both $\mathrm{AC}$ and DC systems; however, additional considerations are required when AC and DC circuits are mixed within the same installation. There are no specific recommendations on the mixing of DC and AC circuits within the same distribution channels or conduits. However, both BS7671 and NEC.725 state that different classes of distribution voltages can be mixed as long as all cables are insulated to the highest voltage rating in the shared distribution channel. Furthermore, the use of warning signs and suitable circuit identification should be considered. Chapter 51 of BS 7671 provides recommendations on the use of warning signs and the convention for labelling $\mathrm{AC}$ and DC circuits; however, further categorisation should be considered to identify different DC voltage levels within an installation.

As more complex DC distribution networks become technically and economically viable, there will be a requirement to maintain and operate these networks safely. These power systems are likely to contain a large number of power converters which can possess stored energy within capacitors that must either be isolated or discharged before performing maintenance work on the network. Therefore, recommendations on the safest approach to isolating and de-energising DC distribution networks should be considered in future standards.

\subsubsection{Fault protection}

The risk of an electric shock can occur in faulted electrical systems where exposed conductive parts become 'live'. To mitigate this risk requires an effective earthing and/or fault detection system that can rapidly resolve the fault before harm is caused to the public or livestock. IEC 60479 documents the effects of current on humans in Figure 5. The level of current flowing through an organic body depends on its impedance and the touch voltage of the live device. Four threshold current ratings are highlighted, these include: DC-1, where minor sensations are felt, DC-2 where muscles may involuntary contract, DC-3 strong muscle contractions and adverse heart effects are experienced, DC-4 irreversible damage can be done which can result in death depending on exposure to the current. 
Figure 5 Effects of current on human beings and livestock

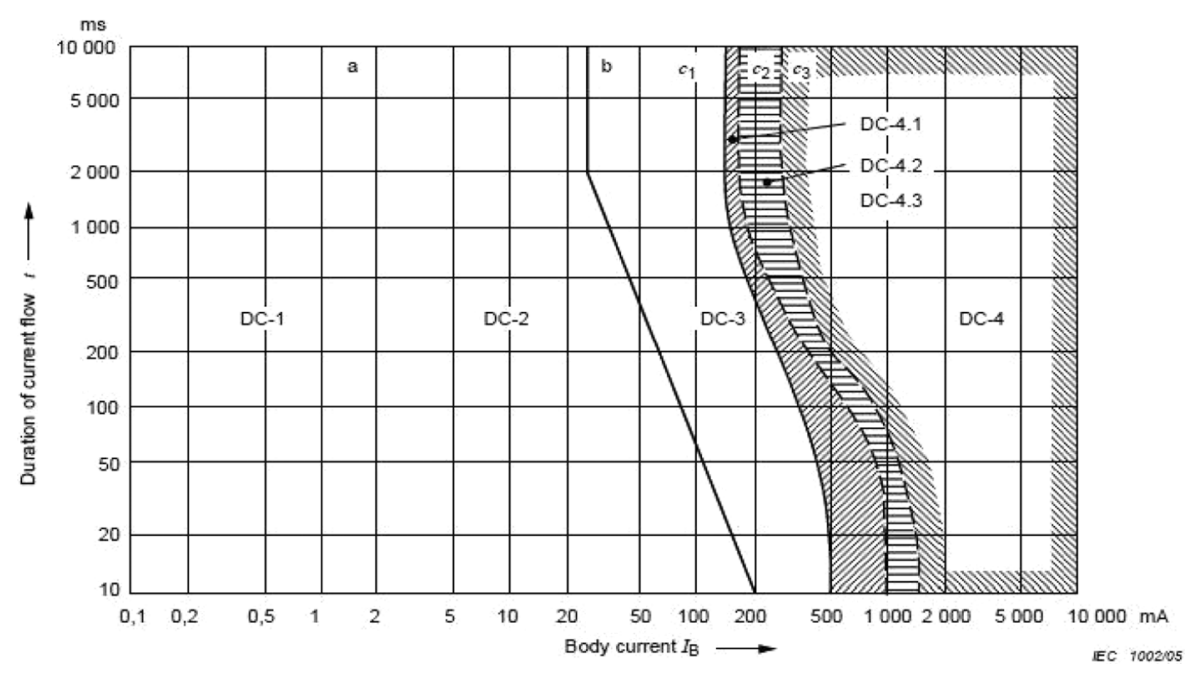

Source: IEC, 2005

It is therefore important to select DC voltage levels and protection such as residual current devices (RCDs) that limit exposure to body currents. It is suggested in Schneider (2013) that voltages under $50 V_{D C}$ do not present danger to humans, this assumes a body impedance of $1 \mathrm{k} \Omega$ and a threshold current of $50 \mathrm{~mA}$. However, other standards prefer a more conservative design such as solar PV systems, where BS EN 62109 specifies that the limitation of current through protective impedance should not exceed $10 \mathrm{~mA} \mathrm{DC}$ to prevent risk of shock (BSI, 2010).

Within occupied spaces, IEC 60598 specifies the provisions for protection against electric shock for LED lighting systems. It states that the control gear voltage should exceed $60 V_{D C}$, and then touch current should be within $2.0 \mathrm{~mA}$. Furthermore, IEC 61347-1 states the provisions for insulation between circuits and accessible conductive parts. With respect to personal computers and USB connections, BS EN 60950-1 states the provisions of protection from hazards for desktop computers. For example, without an overcurrent protection device, output current should be within $8 \mathrm{~A}$ when output DC voltage is less than $30 \mathrm{~V}$. The USB-IF standard (Universal Serial Bus 2.0, 3.0 and type-C Specification) and BS EN 62690-2-1 offer recommendations and guidance on grounding safety.

In larger DC power systems, IEC 60092-507 has standardised protection provision against electric shock, such as maximum breaking time of a protective device (e.g. $\mathrm{U}>400 V_{D C}$, max time is $0.1 \mathrm{~s}$ ), the residual current device operating time should not exceed $40 \mathrm{~ms}$ at a residual current of $150 \mathrm{~mA}$ for marine electrical installations. Whereas BS EN 50328 and BS EN 50633 describe the safety requirements for traction systems, and this includes the fault clearance and withstand time for the converter which is specified as $0.15 \mathrm{~s}$.

IEC 60755 presents three classifications of RCDs: Type AC, Type A and Type B (IEC, 2008). RCDs measure the residual AC current through a coil; however, DC residual currents can cause the coil to saturate and therefore lead to inaccurate readings. Type B RCDs are designed to function with DC residual currents exceeding $6 \mathrm{~mA}$ and are therefore suitable for applications such as PV, EVs and variable speed drives (Kumar \& 
Eichner n.d.). Alternative earth leakage protection solutions include insulation monitoring devices (IMD) that can detect circuit insulation faults and send an alarm to the circuit controller (IEC, 2014). Finally, selecting an extra low voltage DC distribution level can mitigate the safety hazard of residual currents.

Four different earthing configurations are described in BS7671 and depicted in Figure 6: TN-C, TN-S, TT, IT. Each arrangement offers different benefits to LVDC systems; however, BS7671 advises against IT earthing due to the lack of practical experience with these systems. This represents a challenge as recent research suggests that IT systems offer several advantages over traditional earthing arrangements for new LVDC distribution systems, this includes enhanced redundancy and fast touch-voltage reduction (Kaipia et al., 2015). Further research is required to assess the optimum earthing arrangements for specific LVDC applications and this should be reflected in updated wiring codes. Within the NEC, code 250 relates to earthing and bonding of electrical installations and specific recommendations are stated for the sizing of the DC grounding electrode, the requirement for ground fault detection in ungrounded systems and the requirement for labelling the type of grounding configuration at the source of the DC system.

Figure 6 Possible LVDC earthing configurations: all earthing solutions are suitable in either a 2-wire or 3-wire DC distribution system
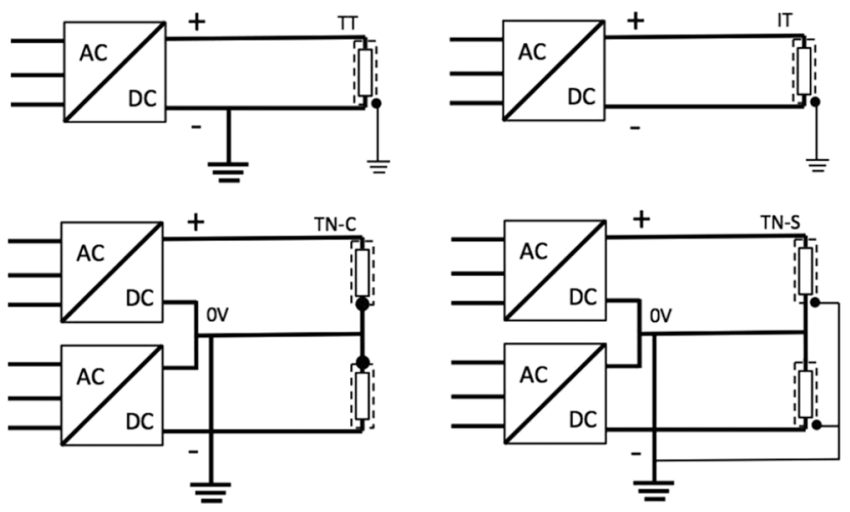

ETSI EN 301605 describes the relevant earthing configurations for $400 V_{D C}$ data and telecom equipment. This standard concludes that TN-S and IT earthing arrangements are most suitable for this application as the PE arrangement can be managed within the telecom or data centre installation and therefore TT earthing can be disregarded (ETSI, 2011). The IT system offers an additional element of redundancy as it can continue to operate after a single pole to ground fault. The fault current in the IT system is limited by a high impedance earth connection, but this system can introduce additional complexity and cost compared to the more traditional TN-S system which is widely used in $\mathrm{AC}$ power systems and is most familiar to electrical installers.

An EV charging station may operate as an isolated DC system or a non-isolated system. In the isolated case, a protective conductor between the DC EV charging station and the vehicle is monitored for loss of electrical continuity. Should a loss occur, the charging station is required to shut-down within $10 \mathrm{~s}$ of detection. For non-isolated systems, the earth conductor is monitored for continuity and the charging station must shut-down within $5 \mathrm{~s}$ of detecting a loss of protective earth. A DC EV charging station is 
required to shut-down in the event of a short circuit, earth leakage, CPU (Central Processing Unit) failure or high system temperatures (BSI, 2014). Any ECP (Exposed Conductive Part) should have a voltage less than $60 \mathrm{~V}$ within 1 second of disconnecting the EV from the electrical supply and the stored energy should be less than $20 \mathrm{~J}$.

\subsection{Corrosion effects}

None of the application-based standards specifically mention or offer recommendations towards the mitigation of electrolytic corrosion effects. However, the IET's "Practical Considerations for DC Distribution" suggests the IT earthing arrangement naturally limits the earth current during faults and therefore is more protective of adjacent metalwork (IET, 2015c).

IEC 50162 provides detailed guidance for the protection against corrosion by stray currents from direct current systems. However, this standard refers to the more traditional uses of DC power and perhaps requires an update that incorporates the recent developments in public LVDC distribution applications such as building level distribution and micro-grids.

The $-48 \mathrm{~V}$ telecom standard uses an earthed positive pole to mitigate against electrolytic corrosion; however, this creates an earth to circuit current flow through human/livestock where contact to a live circuit occurs. The flow of fault current in this direction can cause ventricular fibrillation at half the current value in the circuit to earth direction and is therefore considered a more dangerous distribution configuration and unlikely to be adopted at higher voltage levels (Hirose et al., 2011).

\subsection{Fire safety}

Much of the fire risk associated with DC distribution is similar to AC systems and is mitigated with standard design and protection measures according to national wiring regulations as well as health and safety requirements. However, electrical arcing of DC systems is more severe compared to $\mathrm{AC}$ and therefore additional basic protection requirements may be necessary to avoid exposure to flammable gasses and to ensure appropriate separation between electrical equipment and building material fabric.

Recently, the introduction of DC power sources, such as solar PV, into public distribution systems and buildings has caused increased fire and safety risk to property and personnel responding to fires (Allianz Global Corporate \& Specialty, 2012). The severe arcing of a rooftop solar PV installation under faulted conditions can ignite a fire; therefore, careful installation of solar PV systems and protective equipment is essential. It is also important that personnel responding to a building fire, with a solar PV installation, possess the means to isolate the solar panels and understand when it is safe to apply water to the fire without the risk of electrocution. The American wiring code, NEC 690, presents clear guidelines for the automated shut-down of solar PV systems under faulted conditions. In addition, detailed research into this fire safety risk has been conducted by Underwriters Laboratory and the findings are presented in Backstrom and Dini (2011). These fire safety requirements must also be considered in more complex DC distribution systems which may contain additional DC sources such as battery energy storage and fuel cells. 


\section{Discussion}

This LVDC standards review has focused on civilian technical standards with a particular emphasis on the protection requirements, power quality and safety for existing and emerging LVDC systems. The available LVDC standards discussed in this paper are presented in Table 1 according to application and voltage range. From this presentation, it becomes clearer where standards are lacking for certain applications. The adequacy of existing standards and opportunities for future development can be summarised according to each of the voltage-level categories.

The $<120 V_{D C}$ applications are all commercially available and possess well-defined technical standards with limited barriers to future development. However, the area of residential and occupied space LVDC distribution is complex with many electrical products that require different supply voltages. The use of a universal DC distribution system for occupied spaces requires consideration of the optimum appliance voltage level. We have seen from this review that USB connections operate at $5 \mathrm{~V}$, computers at $12 \mathrm{~V}$ and lighting at $24 \mathrm{~V}$ with some telecom and PoE systems at $48 \mathrm{~V}$. These voltage levels may be suitable for distribution systems up to $1 \mathrm{~kW}$ but in order to avoid converter efficiency losses, room-level DC voltages should be harmonised to a single level that is capable of supplying the diverse electrical appliances. Furthermore, the connection of AC appliances to a DC supply can cause overheating, risk of fire and permanent damage to the $\mathrm{AC}$ product, so it is therefore necessary to design power outlets that accept only $\mathrm{AC}$ or DC appliances.

The applications presented in the 120-400 $V_{D C}$ category are less developed compared to those in the lower voltage range; however, the $400 V_{D C}$ telecom standards provide sufficient information to enable standardised voltage levels and the development of commercial products for these systems. The introduction of the EMerge Alliance $380 V_{D C}$ data centre standard further supports the development of this DC distribution voltage level in building environments. A common theme between these application standards was a lack of preference or guidance towards the most appropriate earthing arrangement. This remains an area of active research that requires a solution offering safety, optimum system performance and reduces the risk of electrolytic corrosion to structural steel within buildings and underground pipes. These applications may span power levels from the tens of kilowatts to hundreds, with either uni-polar or bi-polar converter configurations.

The use of LVDC in utility-level distribution networks such as islanded DC microgrids, hybrid AC/DC micro-grids and last mile DC distribution requires further standardisation. Little experience exists with these larger LVDC networks and as such the optimum design configurations are still an area of research. These networks may draw experience from high power DC traction systems; however, traction systems have large power quality tolerances due to the homogenous electrical load and predictable load requirements. A utility-level LVDC network may have multiple generator types and varying electrical loads that will require tighter power quality tolerances and more sophisticated protection solutions. These networks have the potential to distribute power at the megawatt level and thus far have adopted a bi-polar $\pm 750 V_{D C}$ distribution configuration for the maximum power delivery efficiency. This distribution voltage level also facilitates the separation of $750 V_{D C}$ line into $\pm 375 V_{D C}$ for lower power applications in the Level 2 voltage range. 
In order to recognise the potential environmental and cost benefits that LVDC can bring, it will be necessary to demonstrate an equivalent or higher level of safety compared to AC systems. Further investigation and standardisation are required in the area of fire prevention from DC arcs both within enclosed areas that contain potential flammable gases and with respect to proximity to building fabric materials, especially electrical appliances and power plugs. Furthermore, the performance of maintenance on complex LVDC networks requires careful consideration of the isolation and de-energisation of connected converters on the network prior to commencing work.

Table 4 Available LVDC standards

\begin{tabular}{|c|c|c|c|c|c|}
\hline & Application & Protection criteria & Safety & Power quality & Earthing \& Bonding \\
\hline \multirow{4}{*}{ 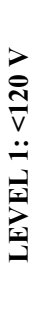 } & USB & $\begin{array}{l}\text { USB-IF }(2.0,3.0 \text {, } \\
\text { Type-C) } \\
\text { BS EN 62680-2-1 }\end{array}$ & $\begin{array}{l}\text { USB-IF }(2.0,3.0, \\
\text { Type-C) } \\
\text { BS EN 62680-2-1 }\end{array}$ & $\begin{array}{l}\text { USB-IF }(2.0,3.0, \\
\text { Type-C) } \\
\text { BS EN 62680-2-1 }\end{array}$ & $\begin{array}{l}\text { USB-IF }(2.0,3.0 \text {, } \\
\text { Type-C) } \\
\text { BS EN } 62680-2-1\end{array}$ \\
\hline & $\begin{array}{l}\text { Telecom } \\
(48 \mathrm{~V})\end{array}$ & $\begin{array}{l}\text { ETSI EN } 300 \\
132-2 \text { TR } 100283\end{array}$ & $\begin{array}{l}\text { ETSI EN } 300 \\
132-2\end{array}$ & $\begin{array}{l}\text { ETSI EN } 300 \\
132-2\end{array}$ & ETSI EN 301605 \\
\hline & $\begin{array}{l}\text { LED } \\
\text { Lighting }\end{array}$ & $\begin{array}{l}\text { BS EN } 61347 \text { 2-13 } \\
\text { BS EN 61347-1 }\end{array}$ & $\begin{array}{l}\text { IEC 60598-1 } \\
\text { IEC 61347-1 }\end{array}$ & BS EN 62384 & IEC 61347-1 \\
\hline & PoE & NEC. 725 & - & IEEE 802.3at & - \\
\hline \multirow{6}{*}{ 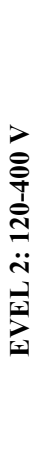 } & Residential & - & $\begin{array}{l}\text { BS7671 } \\
\text { NEC }\end{array}$ & - & $\begin{array}{l}\text { BS7671 } \\
\text { NEC }\end{array}$ \\
\hline & Building & - & BS7671 & - & BS7671 \\
\hline & & & $\mathrm{NEC}$ & & NEC. 250 \\
\hline & $\begin{array}{l}\text { Telecom } \\
(120- \\
400 \mathrm{~V})\end{array}$ & $\begin{array}{l}\text { ETSI } 300 \text { 132-3-1 } \\
\text { ITU-TL.12(00-05) }\end{array}$ & ITU-TL.12(00-05) & $\begin{array}{l}\text { ETSI } 300 \text { 132-3-1 } \\
\text { YD/T2378-2011 } \\
\text { YD/T2089-2016 }\end{array}$ & $\begin{array}{l}\text { ETSI EN } 301605 \\
\text { ITU-TL.12(00-05) }\end{array}$ \\
\hline & $\begin{array}{l}\text { EV } \\
\text { Charging }\end{array}$ & $\begin{array}{l}\text { BS EN 61851- } \\
23: 2014\end{array}$ & $\begin{array}{l}\text { BS EN 61851- } \\
23: 2014\end{array}$ & $\begin{array}{l}\text { BS EN 61851- } \\
23: 2014\end{array}$ & - \\
\hline & $\begin{array}{l}\text { Data } \\
\text { Centre }\end{array}$ & $\begin{array}{l}\text { BS EN 50600-2- } \\
2: 2014\end{array}$ & $\begin{array}{l}\text { BS EN 50600-2- } \\
2: 2014 \text { IEC62040- } \\
5-1\end{array}$ & $\begin{array}{l}\text { BS EN 50600-2- } \\
2: 2014\end{array}$ & ETSI EN 301605 \\
\hline \multirow{5}{*}{ 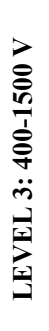 } & Traction & BS EN 50123-7-1 & BS EN 50328 & BS EN 50328 & IEC 62128 \\
\hline & & BS EN 50123-1 & BS EN 50633 & BS EN 50163 & IEC 60364-4-41 \\
\hline & $\begin{array}{l}\text { Public } \\
\text { Networks }\end{array}$ & - & $\begin{array}{l}\text { P2030.10 } \\
\text { NEC. } 712\end{array}$ & - & NEC. 250 \\
\hline & Ship Power & $\begin{array}{l}\text { IEC 60092-507 } \\
\text { ABYC E11 }\end{array}$ & IEC 60092-507 & IEC 60092-101 & - \\
\hline & Solar PV & $\begin{array}{l}\text { BS EN 60269-6 } \\
\text { BS EN 62548-1 }\end{array}$ & $\begin{array}{l}\text { BS EN 62109-1 } \\
\text { EC 60364-4-41 }\end{array}$ & BS EN 62109-1 & IEC 60364-7-712 \\
\hline
\end{tabular}

\section{Conclusion}

This LVDC standards review has highlighted the international organisations that are actively developing design recommendations for LVDC systems and it has presented the available standards with respect to each application's protection requirements, power quality and safety. From this review, it has become clear that stand-alone DC applications 
have well-defined technical standards, but the technical specifications for more complex, integrated networks that will be found within the built environment and public distribution systems are still evolving. Opportunities therefore exist for academics and industry to assist in the formation of the following standards:

- Voltage harmonisation: standard public distribution voltages are required for streetlevel, commercial and residential spaces with consideration to allowable voltage tolerances. From this review, it is suggested that $\pm 750 V_{D C}$ is considered for streetlevel distribution, $\pm 200 V_{D C}\left(380-400 V_{D C}\right)$ is used for building level distribution and a $48 V_{D C}$ room-level voltage is established to offer the most likely compatibility with electrical devices while maintaining a safe voltage level.

- Safety: the physiological effects of current on humans are well understood but greater standardisation of allowable touch voltages and acceptable exposure times should be considered. A better understanding of the optimum (safe and economical) earthing configurations for DC distributions systems is required.

- Protection: the provision of performance guidelines for SSCB and DC RCDs is required for the protection of physical assets and life. Special consideration should be given to the interference of power converters and fault current levels on existing building-level protection systems. Furthermore, the operation of protection systems and its impact on fire safety should be considered with respect to stored energy in converters and batteries.

Once these areas are addressed, product manufacturers and electrical system designers will have the confidence to implement public LVDC distribution and the benefits afforded by LVDC can be recognised.

\section{References}

ABB (2007) ABB Circuit-breakers for Direct Current Applications. Available at: http://www04. abb.com/global/seitp/seitp202.nsf/0/6b16aa3f34983211c125761f004fd7f9/\$file/vol.5.pdf (accessed 3 April 2017)

ABB (2014) The Step Forward Onboard DC Grid. Available at: http://new.abb.com/docs/ librariesprovider91/articles/lm00614-onboard-dc-grid-brochure june2014_1.pdf?sfvrsn=2 (accessed 29 November 2016).

Adefarati, T. and Bansal, R.C. (2016) 'Integration of renewable distributed generators into the distribution system: a review', IET Renewable Power Generation, Vol. 10, No. 7, pp.873-884.

Ailee, G. and Tschudi, W. (2012) "Edison redux: 380 Vdc brings reliability and efficiency to sustainable data centers," IEEE Power Energy Mag., Vol. 10, No. 6, pp.50-59.

Alliance for Sustainable Colorado (2016) The Alliance Center dcProject. Available at: http://www.sustainablecolorado.org/what-we-do/building-innovation/dc-project/ (accessed November 10, 2016).

Allianz Global Corporate \& Specialty (2012) 'Understanding the fire hazards of photovoltaic systems', Allianz Risk Consulting, Germany, Vol. 8, pp.1-7.

Antoniou, D., Tzimas, A. and Rowland, S.M. (2013) 'DC utilization of existing LVAC distribution cables', 2013 IEEE Electrical Insulation Conference, Ottawa, Ontario, Canada, pp.518-522.

Backstrom, R. and Dini, D. (2011) Firefighter Safety and Photovoltaic Installations Research Project, Available at: http://www.ul.com/global/documents/offerings/industries/ buildingmaterials/fireservice/PV-FF_SafetyFinalReport.pdf (Accessed 29 November 2016). 
BSI (2007), BS EN 50163:2004+A1:2007: Railway Applications - Supply Voltages of Traction Systems. Available at: https://bsol.bsigroup.com/ (Accessed: $5^{\text {th }}$ April 2017).

BSI (2010), BS EN 62109-1:2010: Safety of Power Converters for Use in Photovoltaic Power Systems. General Requirements. Available at: https://bsol.bsigroup.com/ (Accessed: $5^{\text {th }}$ April 2017).

BSI (2012), BS EN 60269-6: Low-voltage fuses. Part 6. Supplementary requirements for fuse-links for the protection of solar photovoltaic energy systems. Available at: https://bsol.bsigroup. com/ (Accessed: $5^{\text {th }}$ April 2017).

BSI (2014), BS EN 61851-1:2011: Electric Vehicle Conductive Charging System. Available at: https://bsol.bsigroup.com/ (Accessed: $5^{\text {th }}$ April 2017).

BSI (2015), BS EN 62680-2-1:2015 Universal Serial Bus interfaces for data and power. Universal Serial Bus Specification, Revision 2.0 (TA 14). Available at: https://bsol.bsigroup.com/ (Accessed: $5^{\text {th }}$ April 2017).

Bureau of Indian Standards (2011), SP 30: National Electric Code 2011. Available at: https://archive.org/details/gov.in.is.sp.30.2011 (Accessed: $5^{\text {th }}$ April 2017).

Dragicevic, T., Lu, X., Vasquez, J.C. and Guerrero, J.M. (2016) 'DC microgrids-part II: a review of power architectures, applications, and standardization issues', IEEE Transaction on Power Electronics, Vol. 31, No. 5, pp.3528-3549.

Eaton (2015), Bussmann Series: Technical Data 10414. Available at: http://www.cooperindustries. $\mathrm{com} /$ content/dam/public/bussmann/Electrical/Resources/product-datasheets-b/bus-ele-ds10414-chsf.pdf (Accessed: $5^{\text {th }}$ April 2017).

Eaton (2016), Serie G Global Circuit Breakers: Molded Case Circuit Breakers (Catalog). Available at: http://www.eaton.com/Eaton/ProductsServices/Electrical/ProductsandServices/ CircuitProtection/ MoldedCaseCircuitBreakers/SeriesGGlobalCircuitBreakers/index.htm\#tabs -2 (Accessed: $5^{\text {th }}$ April 2017).

Elsayed, A.T., Mohamed, A.A. and Mohammed, O.A. (2015) 'DC microgrids and distribution systems: an overview', Electric Power Systems Research, Vol. 119, pp.407-417.

EMerge Alliance (2016) EMerge Alliance. Available at: http://www.emergealliance.org/Home.aspx (Accessed 29 November 2016).

Emhemed, A.A.S. and Burt, G.M. (2013), 'The effectiveness of using IEC61660 for characterising short-circuit currents of future low voltage DC distribution networks', 22nd International Conference on Electricity Distribution, Stockholm, 10-13 June 2013, pp.10-13.

Emhemed, A.A.S. and Burt, G.M. (2014) 'An advanced protection scheme for enabling an LVDC last mile distribution network', IEEE Transactions on Smart Grid, Vol. 5, No. 5, pp.2602-2609.

Emhemed, A.A.S., Fong, K., Fletcher, S. and Burt, G.M. (2016) 'Validation of fast and selective protection scheme for an LVDC distribution network', IEEE Transactions on Power Delivery. [Online Early Access]. doi 10.1109/TPWRD.2016.2593941. Published Online 2016: http://ieeexplore.ieee.org/stamp/stamp.jsp?arnumber=7519032 (Accessed: $5^{\text {th }}$ April 2017).

ETSI (2011), ETSI EN 300 132-3-0: Environmental Engineering (EE); Earthing and Bonding of 400 VDC Data and Telecom (ICT) Equipment. Available at: http://www.etsi.org (Accessed: $5^{\text {th }}$ April 2017).

Fachot, M. (2015) DC Takes the Driving Seat: Low Voltage Direct Current has Benefits for Both Developed and Developing Countries. Available at: http://iecetech.org/issue/2015-06/DCtakes-the-driving-seat (accessed 29 November 2016).

Genovese, A., Ortenzi, F. and Villante, C. (2015) 'On the energy efficiency of quick DC vehicle battery charging', EVS28 International Electric Vehicle Symposium and Exhibition, KINTEX, Korea, May 3-6, 2015, pp.1-7.

Germanischer Lloyd SE (2016), Rules for classification and construction - ship technology. Available at: http://rules.dnvgl.com/docs/pdf/gl/maritimerules/gl_i-1-3_e_new.pdf (Accessed: $5^{\text {th }}$ April 2017) 
Goodman, C.J. (2006) 'Overview of electric railway systems and the calculation of train performance', 9th IET Professional Development Course on Electric Traction Systems, Manchester, UK, 6-9 Nov 2006, pp.13-36.

Hebner, R.E., Uriarte, F.M., Kwasinski, A., Gattozzi, A.L., Estes, H.B., Anwar, A., Cairoli, P., Dougal, R.A., Feng, X., Chou, H-M., Thomas, L.J., Pipattanasomporn, M., Rahman, S., Katiraei, F., Steurer, M., Faruque, M.O., Ramos, G.A., Mousavi, M.J. and Mccoy, T.J. (2015) 'Technical cross-fertilization between terrestrial microgrids and ship power systems', Journal of Modern Power Systems and Clean Energy, Vol. 4, No. 2, pp.161-179.

Hewlett-Packard et al. (2013), Universal Serial Bus 3.1 Specification. Available at: http://www.usb.org/developers/docs/ (Accessed: $5^{\text {th }}$ April 2017).

Hewlett-Packard et al. (2016), Universal Serial Bus Type-C Cable and Connector Specification. Available at: http://www.usb.org/developers/usbtypec/ (Accessed: $5^{\text {th }}$ April 2017).

Hirose, K., Tanaka, T. and Babasaki, T. (2011) 'Grounding concept considerations and recommendations for $400 \mathrm{VDC}$ distribution system', INTELEC, International Telecommunications Energy Conference (Proceedings).

IEC (2009), IEC 60038:2009 ED 7: IEC Standard Voltages. Available at: https://bsol.bsigroup.com (Accessed $5^{\text {th }}$ April 2017).

IEC (2005), IEC TS 60479-1:2005 Effects of current on human beings and livestock - Part 1: General aspects. Available at: https://webstore.iec.ch/publication/2219 (Accessed: 5th April 2017).

IEC (2008), IEC TR 60755:2008 General requirements for residual current operated protective devices. Available at: https://webstore.iec.ch/publication/3404 (Accessed 5th April 2017).

IEC (2014), IEC 61557-8:2014 Electrical Safety in Low Voltage Distribution Systems up to $1000 \mathrm{~V}$ ac and $1500 \mathrm{~V} \mathrm{dc}$ - Equipment for Testing, Measuring or Monitoring of Protective Measures Part 8: Insulation Monitoring Devices for IT Systems. Available at: https://webstore.iec.ch/ publication/5582 (Accessed: $5^{\text {th }}$ April 2017).

IEC (2015), IEC 61892-1:2015 Electrical Installations of Ships and of Mobile and Fixed Offshore Units. Available at: https://webstore.iec.ch/publication/22872 (Accessed: $5^{\text {th }}$ April 2017).

IEC (2017) Standardization Management Board. Available at: http://www.iec.ch/dyn/www/ f?p=103:79:0::::FSP_ORG_ID,FSP_LANG_ID:3228,25 (accessed 14 November 2017).

IEC SEG4 (2016), Low Voltage Direct Current Applications, Distribution and Safety for use in Developed and Developing Economies. Available at: http://www.iec.ch/dyn/www/f?p=103: 186:662361467777::::FSP_ORG_ID,FSP_LANG_ID:11901,25/docs/3713e.pdf (Accessed: $5^{\text {th }}$ April 2017).

IEEE (2016) Standard for DC Microgrid for Rural and Remote Access Applications. P2030.10. Available at: https://standards.ieee.org/develop/project/2030.10.html (accessed 29 November 2016).

IET (2013). Code of Practice for the Application of LED Lighting Systems. London: Institute of Engineering \& Technology.

IET (2015a), BS 7671:2008+A3:2015: 17th Wiring Regulations. Available at: http:/electrical. theiet.org/wiring-regulations/index.cfm?referrer=/wiring-regulations/index.cfm (Accessed: $5^{\text {th }}$ April 2017).

IET (2015b), Code of Practice for Low \& Extra Low Voltage Direct Current Power Distribution in Buildings. London: Institute of Engineering \& Technology.

IET (2015c), Practical Considerations for DC Installations. Available at: http://www.theiet.org/ resources/standards/dc-technical.cfm (Accessed: $5^{\text {th }}$ April 2017).

USB Implementers Forum (2017), Universal Serial Bus Power Delivery Specification Revision 2.0, Version 1.3. Available at: http://www.usb.org/developers/docs/usb20_docs/ (Accessed: $5^{\text {th }}$ April 2017).

Intel (2004) ATX Specification. Available at: http://www.formfactors.org/developer/specs/ atx2_2.pdf (accessed 29 November 2016). 
International Electrotechnical Commission (IEC) (2000) IEC/TR 61660-3:2000: Short-circuit Currents in DC Auxiliary Installations in Power Stations and Substations. Examples for the Calculation of Short-circuit Currents and Calculation of Effects.

International Energy Agency (2016), Global EV Outlook 2016 Beyond one million electric cars. Available at: https://www.iea.org/publications/freepublications/publication/Global_EV_Out look_2016.pdf (Accessed: $5^{\text {th }}$ April 2017).

Kaipia, T. et al. (2015) 'Effect of voltage level selection on earthing and protection of LVDC distribution systems', 11th IET International Conference on AC and DC Power Transmission, Birmingham, U.K., p.084 (8.). Available at: http://digital-library.theiet.org/content/ conferences/10.1049/cp.2015.0057 (Accessed: $5^{\text {th }}$ April 2017)

Kaipia, T. et al. (2016) 'Lvdc Rules - Towards Industrial-Scale Application of Low-Voltage Direct Current in Public Power Distribution', CIRED Workshop, Helsinki, Finland, 14-15 June 2016.

Kumar, K.A. and Eichner, J. Guidance on Proper Residual Current Device Selection for Solar Inverters. Avaiable at: http://www.technosun.com/es/descargas/SCHNEIDER-CONEXT-notacorriente-residual-EN.pdf (accessed 29 November 2016).

Littelfuse (2012), Class L - KLLU Series Fuses: Data Sheet. Available at: http://www.littelfuse. $\mathrm{com} /$ products/fuses/industrial-power-fuses/class-l-fuses/kllu.aspx (Accessed:5th April 2017).

Lobenstein, R.W. and Sulzberger, C. (2008) 'Eyewitness To Dc History', IEEE Power \& Engineering Magazine, May/June 2008. DOI: 10.1109/MPE.2008.920421.

Lyons, R. (2011) 'Sizing Fuses for Photovoltaic Systems per the National Electrical Code'. Photovoltaic Protection, Note 5, Issue 1. Available at: http://o.b5z.net/i/u/10069179/f/TTPVPN5-Sizing-Fuses-of-Photovoltaic-Systems-per-NEC-Tech-Topic_1_.pdf (Accessed: 5th April 2017).

Mahela, O. P., \& Shaik, A. G. (2016). Comprehensive overview of grid interfaced wind energy generation systems. Renewable and Sustainable Energy Reviews, 57, 260-281. ISSN: 13640321. http://doi.org/10.1016/j.rser.2015.12.048

Monadi, M. et al. (2015) 'Protection of AC and DC distribution systems Embedding distributed energy resources: a comparative review and analysis', Renewable and Sustainable Energy Reviews, Vol. 51, pp.1578-1593.

National Fire Protection Association (2017), National Electric Code (NFPA 70). Available: http://www.nfpa.org/codes-and-standards/all-codes-and-standards/list-of-codes-and-standards? mode $=$ code \&code $=70$ (Accessed: $5^{\text {th }}$ April 2017)

Nuutinen, P. (2015) Power Electronic Converters in Low-voltage Direct Current Distribution. PhD Thesis. Lappeenranta University of Technology. Available at: http://www.doria.fi/bitstream/ handle/10024/117972/Pasi\%20Nuutinen\%20A4.pdf?sequence=2 (Accessed: $5^{\text {th }}$ April 2017)

Nuutinen, P. et al. (2014) 'Research site for low-voltage direct current distribution in a utility structure, functions, and operation', IEEE Transactions on Smart Grid, Vol.5, No. 5, pp.2574-2582. DOI: 10.1109/TSG.2014.2308365.

Pires, C.L., Nabeta, S.I. and Cardoso, J.R. (2009) 'DC traction load flow including AC distribution network', IET Electric Power Applications, Vol.3, Issue 4, pp.289-297. doi: doi: 10.1049/ietepa.2008.0147

Purdue University (2009), Stability of Power Electronic Based Distribution Systems. Available at: https://engineering.purdue.edu/ECE/Research/Areas/PEDS/SPEBPDS.html (Accessed: $5^{\text {th }}$ April 2017).

Ravula, S. (2015) Direct Current Based Power Distribution Architectures for Commercial Buildings. Available at: http://www.energy.ca.gov/research/epic/documents/2015-1203_symposium/presentations/Session_1A_4_Sharmila_Ravula_Robert_Bosch.pdf (Accessed November 10, 2016).

Schneider (2013) Circuit Breakers for Direct Current Applications. Avaiable at: http:/oreo. schneider-electric.com/flipFlop/415304948/files/docs/all.pdf (accessed 29 November 2016). 
Schneider (2017), A9N61538 miniature circuit breaker. Available at: http://www.schneiderelectric.com/en/product/A9N61524/miniature-circuit-breaker---c60h---2-poles---4-a---c-curve/ (Accessed: $5^{\text {th }}$ April 2017)

Shehabi, A. et al. (2016) United States Data Center Energy Usage Report, (June). Available at: https://datacenters.lbl.gov/sites/all/files/DataCenterEnergyReport2016_0.pdf (accessed 29 November 2016).

Smith, K.A. et al. (2016) 'Feasibility of direct current street lighting \& integrated electric vehicle charging points', IET Hybrid Electric Vehicle Conference 2016. London, UK 2-3 November, pp.1-6.

Tabari, M. and Yazdani, A. (2013). 'A DC distribution system for power system integration of plug-in hybrid electric vehicles', IEEE Power \& Energy Society General Meeting, Vol. 5, No.5, pp.2564-2573.

The European Parliament and the Council of the European Union (2006) Directive 2006/95/EC of the European Parliament and of the Council on the Harmonnisation of the Laws of Member States Relating to Electrical Equipment Designed for Use within Certain Voltage Limits.

Tiku, D. (2014) 'DC power transmission: Mercury-arc to thyristor HVdc valves [History]', IEEE Power and Energy Magazine, Vol. 12, No. 2, pp.76-96.

TOSHIBA (2014), Traction and Auxiliary Power Systems, Available at: https://www.toshiba.co.jp/ sis/railwaysystem/en/products/catalog/pdf/traction_and_auxiliary_power_systems.pdf (Accessed: $5^{\text {th }}$ April 2017).

TU Delft (2016) DCSMART. Available at: http://dcsmart.tudelft.nl/project-summary/ (accessed 29 November 2016).

UL (2015) Power over Ethernet Lighting - Evolution or Revolution? Avaible at: $\mathrm{http} / / /$ smartcitiescouncil.com/system/tdf/main/public_resources/Power-over-Ethernet-whitepaper_final.pdf?file $=1 \&$ type $=$ node $\& i d=3502$ (accessed 29 November 2016).

USB 3.0 Promoter Group (2014) Universal Serial Bus Type-C Cable and Connector Specification, pp.1-171.

Wiebe, E. (2013) 'DC in the Home: Industry Connections Activity Initiation Document', Version 1.2, 12 June. Available at: https://standards.ieee.org/about/sasb/iccom/IC13-005-02_DC_in_ the Home.pdf (Accessed: $5^{\text {th }}$ April 2017).

Wunder, B. et al. (2014) Energy efficient DC-grids for commercial buildings. 2014 IEEE $36^{\text {th }}$ International Telecommunications Energy Conference (INTELEC). Vancouver, Canada, 28 Sept -02 Oct. pp.1-8.

Yamada, M. and Stober, K. (2015), Adoption of Light-Emitting Diodes in Common Lighting Applications. Available at: https://energy.gov/sites/prod/files/2015/07/f24/led-adoption-report 2015.pdf (Accessed: $5^{\text {th }}$ April 2017). 